\title{
O invisível no plano cinematográfico: rastros de Benjamin e Bergson
}

\section{Suzana Kilpp}

Doutora; Universidade do Vale do Rio dos Sinos

sukilp@unisinos.br

\section{Ricardo Weschenfelder}

Doutorando; Universidade do Vale do Rio dos Sinos

ricavertice@yahoo.com.br

\section{Resumo}

Neste artigo exploramos formas de presença e ausência nos enquadramentos e na percepção do espectador a partir de cenas e quadros do filme $O$ Eclipse (1962) de Michelangelo Antonioni. Constatamos a intenção do cineasta em realizar, nesse filme, o que denominamos de 'eclipse de visualidade', isto é, rastros entre o visível e o invisível na montagem dos planos cinematográficos. O tempo intrínseco da montagem faz com que os quadros retornem de outra maneira, remetam a outros quadros e, sobretudo, deixem rastros na passagem das imagens e dos sons em movimento. Nesta discussão sobre rastros do invisível e a memória do visível, aprofundamos os conceitos especulares de rastro e aura em Benjamin e os cotejamos com os conceitos de tempo e memória de Bergson.

\section{Palavras-chave}

Cinema. Plano cinematográfico. Eclipse de visualidade. Rastros. Memória.

\section{Introdução}

Este artigo reflete um momento da pesquisa sobre os rastros do invisível no plano cinematográfico, que tem como corpus cenas e quadros do filme $O$ Eclipse (1962) de Michelangelo Antonioni. Nas cenas finais do filme, o cineasta coloca as personagens para fora de cena e a câmera se volta para os detalhes de objetos que as personagens manipularam e de lugares que percorreram ao longo da narrativa. Antonioni realizou, nesses planos, um eclipse da visualidade presente nos planos anteriores, apontando então para os rastros do que neles estava oculto e, a nosso ver, para o que da memória das personagens esteve agindo 
nas relações estabelecidas entre elas durante a narrativa. Assim, a metáfora aciona a lembrança de uma série de imagens que se eclipsam, aos pares, umas às outras: claras e escuras; presentes e ausentes; visíveis e invisíveis.

0 eclipse é o fenômeno astronômico, visto da Terra, em que dois corpos celestes são sobrepostos, principalmente o Sol e a Lua, deixando um deles "por trás" do outro, tornandose esse invisível, parcialmente oculto, eclipsado por aquele.

A questão que nos colocamos foi: como funciona, no cinema, a dialética da presença e da ausência, a das imagens do filme e a das imagens "percebidas" pelo espectador?

Trataremos daquilo que nessa dialética concerne ao enquadramento e à percepção. Ou seja, no artigo teceremos considerações sobre aquilo que está, aparentemente ou temporariamente, invisível ao espectador em um quadro ou plano de um filme, e, que, no entanto, age sobre o que ele "vê". Esse "invisível", mas presumido, situa-se no que as teorias do cinema tendem a chamar de fora de campo, ou, no mais das vezes, de extracampo.

A noção de extracampo é controversa entre cineastas e teóricos de cinema, que vão de Balazs (2008) a Bonitizer (2007), passando por Eisenstein (2002), André Bazin (1991) e Deleuze (1985). Destacamos duas vertentes que nos interessam: a que entende a imagem do extracampo como "entre-imagem", isto é, como uma imagem de intervalo, lacunar, que está, entretanto, entre outras imagens do quadro ou plano (essa perspectiva é compartilhada por Bellour (1990), Vertov (2008), Eisenstein (2002) e Musterbeng (2008); e a que a entende como imagem "centrífuga",1 ou seja, uma imagem para fora da imagem, que extrapola os limites do enquadramento (nessa perspectiva estão Bazin (1991), Crary (2004), Bonitzer (2007), Deleuze (1985) e Godard (apud GRÜNNEWALD, 1969).

No entanto, queremos propor uma discussão não sobre imagens que estejam fora do campo visível do espectador (tenha ou não esse "lugar" ou "tempo" a ver com a controversa noção de extracampo), mas, enfaticamente, sobre porque e como essas imagens "comparecem" no quadro ou plano, ou seja, como elas se tornam perceptíveis no quadro ou plano. Nessa ambiência, trata-se, talvez, de conjeturar sobre a produção de presença (GUMBRECHT, 2010). Ou então, como preferimos, operar com os conceitos de rastro e aura (BENJAMIN, 2006), e de tempo e memória (BERGSON, 2011).

Aura e rastro são alegorias de Benjamin para a percepção do tempo, ou melhor, para a trama de espaço e tempo nas imagens, que se perdem e são retomadas em diferentes mo-

\footnotetext{
1 Centrífuga é, segundo Bazin (1991), a característica da imagem cinematográfica, pois a tendência da imagem em movimento é extrapolar o quadro, sair do enquadramento. Já na pintura, a imagem é centrípeta, ou seja, a imagem age em profundidade, no interior do quadro.
} 
mentos da narração. 0 conceito de rastro nos ajuda a ver o plano cinematográfico como imagem de limiar, que confunde o dentro e o fora na arquitetura do quadro e convoca uma miragem de diferentes tempos que coexistem na imagem. Os conceitos de memória e tempo em Bergson (2011), por sua vez, estão colocados para confrontar a ideia cartesiana que entende a montagem de cinema como justaposição de imagens, em noções como antes e depois do plano e dentro e fora do quadro.

"Plano" é o termo técnico usado no cinema para designar estritamente a imagem enquadrada e situada entre dois cortes. Porém, como alegoria, ele deve ser entendido aqui como camada, nível, estado e dimensão da imagem. Nesta outra dimensão ou natureza, o plano invisível se configura como o nosso objeto.

Assim, o plano passa a ser uma multiplicidade heterogênea e imanente, que age de dentro para fora do visível, com duração e memória próprias. Ele não deve ser reduzido ao enquadrado e sucessivo que leva a narrativa adiante: ele é uma multiplicidade de imagens dobrando-se no tempo, que se fixam em um quadro, mas que se prolongam entre os quadros e para além deles. Isso implica, portanto, um outro entendimento da imagem espacializada (a imagem de um instante do tempo, que segue desenrolando-se) e implica lembrar ou imaginar outras imagens virtualmente também se desenrolando na duração e que são evocadas pelo espectador a partir de rastros que deixam no quadro ou no plano visíveis (espacializados).

\section{A dialética do invisível a partir de Benjamin}

Na esteira de Benjamin, Didi-Huberman (2010) enfatiza que o olhar resulta de um jogo entre a proximidade (do visível) e a distância (do invisível, que ou deixa rastros ou vestígios no visível, ou que se relaciona à experiência estética e aurática do vidente), sendo que ele não se reduz ao olhar um objeto e nele ver alguma forma realizada (visível), pois ele se estende, como olhar, à produção do sentido de visto e de não visto. Haver-se-ia de produzir, nos dois casos, uma "dupla distância" do vidente em relação ao visível para que se efetivasse uma crítica da imagem, ou, para que se produzisse uma imagem dialética (crítica) das imagens. Essa distância seria de espaço e de tempo, assim como a distância que há entre estrelas que inventamos agrupar ou constelar em mapas celestes. Benjamin diria, alegoricamente, que as estrelas estariam para as constelações da mesma forma que as coisas (imagens) estariam para as ideias que temos delas. 
Trata-se da visão miraculosa, como uma epifania, no sentido do "culto" que a imagem pode evocar no espectador ou contemplador. A experiência aurática do sujeito passa por, metaforicamente, tocar e sentir com os olhos, e sentir o tempo anacrônico da imagem, sendo o anacronismo, no sentido a ele atribuído por Agamben (2009), uma forma de ser contemporâneo em que o sujeito adere ao presente e, ao mesmo tempo, se faz distante dele, e implica manter uma relação singular com o seu próprio tempo.

Essa visão é bem benjaminiana e reporta à circunstância inexorável de se estar no presente espacial da imagem e distante no tempo da imagem, sendo o pensamento o espaçamento necessário à percepção da ação do tempo sobre as imagens.

Aura, em Benjamin (2012), é a presença de algo que está distante por mais perto que esteja, e o rastro é a presença de algo que está perto, mas que já está em outro lugar. Aura e rastro estão relacionados entre si e sob a ingerência do tempo sobre o movimento nos e dos diferentes planos de visualidade, e ambos produzem no vidente um sentimento de perda e de ausência (falta) do que não está imediatamente visível, seja da história, seja dos objetos, seja das imagens.

Para Benjamin (2012), na modernidade, a técnica (nossa segunda natureza) cegou o vidente quanto ao visível: na modernidade, o visível já não informava sobre a primeira natureza, mas o vidente seguia, erroneamente, auscultando-a nas imagens técnicas. Entretanto, tal circunstância demandaria um outro olhar.

Assim como as imagens tradicionais (pintura e escultura) teriam nos ensinado sobre a natureza do mundo (nossa primeira natureza), as imagens técnicas (fotografia e cinema) deveriam nos ensinar sobre a natureza técnica do mundo (nossa segunda natureza). Para tanto, seria necessário, primeiro, dar-se conta disso; depois, desabituar o olhar, que insistia em encontrar e representar nossa primeira natureza onde ela já não estava - mas insinuavase, porque a técnica discretizava-se no visível -; e daí em diante era preciso rastrear a técnica (invisível) disfarçada no visível.

Por isso, Benjamin (2012) procurou "ver" (ou, mais precisamente, em seus termos, "mostrar") o que estava fora da vista, o que estava, aparentemente, ausente; mas que podia ser perscrutado nas entrelinhas da forma e da técnica, basicamente, na montagem: nas técnicas de fragmentação do todo e da montagem das partes. Aura e rastro não são, portanto, conceitos opostos. São especulares. 
Complementando a ideia, quanto à imagem dialética² ${ }^{2}$ Benjamin $(2006$, p. 505) diz, por exemplo, que

[...] não é que o passado lança sua luz sobre o presente ou que o presente lança luz sobre o passado; mas a imagem é aquilo em que o ocorrido encontra o agora num lampejo, formando uma constelação. Em outras palavras: a imagem é a dialética na imobilidade. Pois, enquanto a relação do presente com o passado é puramente temporal, a do ocorrido com o agora é dialética - não de natureza temporal, mas imagética.

Ou seja, o conceito de imagem dialética participa da filosofia de Walter Benjamin enquanto pensa a história e a estética como constelações de imagens, que brilham e se apagam, dialeticamente, no tempo. Por isso, devemos retomar, agora, o conceito de história proposto por Benjamin (1989) e explicar melhor nosso entendimento sobre as imagens dialéticas que nos interessam aqui, relacionadas à aura e ao rastro.

Benjamin (1989) constatou que perduravam em seu próprio presente (início do século XX) imagens arcaicas, e se deteve em analisar aquelas que prenunciavam o futuro da técnica (industrial), sonhada ou imaginada na Paris do século XVIII. Considerou a possibilidade de haver nas imagens da modernidade um encontro do passado com o presente, um "encontro secreto", fugaz e misterioso, entre "o ocorrido e o agora". Benjamin (1989) fala em "sopro", "eco", "lampejo" do passado no presente; e, por isso, para o historiador não se trataria de analisar o passado que foi, mas aquele que perdura no presente como rastro.

Como lembra Gagnebin (2012) a partir de Benjamin, para não ser apagado e esquecido, o passado deixa rastros, e a missão do pesquisador deveria ser a de reconstruir o passado a partir do fragmento, do sinal, do vestígio encontrado no presente para, aí sim, dar um salto para projetar o futuro. Quando Benjamin (2012) escreve, por exemplo, sobre o último suspiro do retrato/pintura frente à técnica fotográfica, ele recorre, justamente, aos rastros do retrato na fotografia, ou seja, ao retrato como forma característica da pintura, que é estendida e que perdura na fotografia, ao menos em seus primórdios.

Para ultrapassar essa perspectiva saudosista e enganadora seria preciso parar de pensar o passado como algo que foi e que precedeu o presente; sentir ou imaginar sua potência, latente; e prospectar criativamente outros futuros, nos quais a potência do passado subsumido pela história realizada ainda age sobre o presente. Ou seja, reconhecer a força messiânica do passado.

\footnotetext{
2 Conforme Bolle (1994), o conceito de "imagem dialética" foi sendo modificado e aperfeiçoado por Benjamin no período de 1927 a 1935.
} 
É nessa direção que Benjamin (1989) fala em "dialética na imobilidade" como a imagem de um pião, objeto multifacetado que gira sobre si mesmo na imobilidade da diferença de suas faces. Para ele, a imagem dialética é explosão de "agoras", ou seja, um tempo carregado de vários tempos, que modifica e desestabiliza a percepção do presente: os "agoras" são contemporaneidades, sempre em nível sensorial, de diferentes tempos.

A ação da memória - que, a partir do fragmento oscila, na distância, entre presença e ausência - é o que possibilitaria o despertar ${ }^{3}$ da imagem dialética, a conexão de tempos remotos e a existência de "agoras", sendo que, para Benjamin, a memória histórica não seria a que reproduz ou restaura o passado como de fato aconteceu, mas, sobretudo, a que inventaria e organizaria "um" passado.

O colecionador, personagem conceitual típico do pensamento benjaminiano, além de apropriar-se de objetos antigos, desacelera o tempo presente e cria outro contexto para os objetos, como o fazem o mago e o visionário, que veem, no objeto, coisas mágicas e invisíveis. 0 colecionador é um especialista da memória, pois cultua e inventa narrativas do objeto, que são até mais interessantes do que o próprio objeto. Nessa perspectiva, afinal, a que se relaciona a memória: ao objeto ou ao colecionador?

Para responder a essa questão convocamos para esse artigo as contribuições de Henri Bergson, pois, como anunciamos, perscrutamos os rastros do invisível no plano cinematográfico a partir de uma perspectiva que se encontra entre Benjamin e Bergson.

\section{A ação da memória a partir de Bergson}

Na leitura de Benjamin feita por Didi-Huberman (2010), aura e rastro falam, alegoricamente, sobre as distâncias entre o espaço e o tempo, na medida em que, ultrapassam, por força da memória, o momento de visualização da imagem no presente. E, a nosso ver, presentifica-se uma (in) formação que está e não está diante dos olhos, que se (des) (in) forma na "dupla distância" intermitente do tempo, no cinema, por exemplo.

Já para Bergson (2011, p. 69) memória é “[...] a sobrevivência das imagens passadas, e estas imagens irão se misturar a percepções do presente e poderão inclusive substituílas.". A imagem no cinema, sempre em movimento - movimento simulado pela técnica de projeção, é bem verdade -, encarna muito bem o tempo bergsoniano e a lembrança produzi-

\footnotetext{
3 Colocamos aqui o termo despertar para sugerir a relação que Benjamin (2007) estabelece com Freud, do despertar como transição entre sonho e vigília. Quando acordamos, o sonho se desfaz, se perde; porém ainda se faz presente, como rastro, ao longo do dia, em forma de narrativa e interpretação. Em Benjamin, a posição política do intelectual, a sua consciência, é o que despertaria a sociedade do sonho coletivo edificado pelo capitalismo.
} 
da na consciência a partir da imagem, pois, nesse movimento, uma imagem não substitui nem apaga a precedente no fluxo de um filme. Tampouco existe, na memória, um conjunto fechado de imagens datadas armazenadas. Ao registrar uma imagem que "passa" no presente, nossa memória sobrepõe a essa imagem, imagens-lembrança, ou seja, imagens latentes, que podem ser entendidas como "lembranças do presente" - que nunca deixaram de existir, apenas deixaram de ser úteis - que a "completam", que a envolvem. De outro lado, as imagens-lembrança, que estavam, por sua vez, no plano virtual, na duração da memória pura, são atualizadas e se materializam na percepção de imagens do presente.

Para Bergson (2011), já o corpo é imagem: ele é, na verdade, a imagem central que age e é afetada pelas outras imagens do universo de imagens. A percepção das coisas, nesse sentido, é impregnada de imagens-lembrança que temos dessa coisa. A memória faz-se, assim, presente e ativa na percepção, afetando a relação do vidente com o visível, por exemplo, quando ou enquanto o leva a intuir (ou imaginar) a presença no visível de algo que não está lá de fato em seu próprio espaço e tempo histórico, em sua materialidade inconteste.

Para Bergson (2011), as imagens diferenciam-se, ontologicamente, em grau e natureza. No plano da matéria estão localizadas as diferenças de grau de uma mesma duração, sendo que é na matéria que ela se atualiza diferenciando-se de si mesma, no espaço, o que implica que o pesquisador interessado nessa imagem específica deve perscrutar o que dela dura no conjunto rizomático de suas diferenciações de si. Implica sobretudo pensar que todas as coisas tem dois modos: o seu modo de ser e o seu modo de agir. Ou seja: em seu modo de ser a coisa é (virtualmente) tal ou qual; em seu modo de agir, ela se atualiza assim ou assado na matéria. Esse é, segundo Bergson (2011), o modo adequado e preciso de se colocar o pesquisador na duração das coisas que pesquisa: problematizar verdadeiramente uma coisa qualquer, constituir um verdadeiro objeto de pesquisa que seja o misto de sua virtualidade e de suas atualizações na matéria. Por exemplo: a) o que é a tendência virtual (a duração no tempo) do plano no cinema?; b) como o plano age ou se atualiza na materialidade espacial dos filmes? Eis aí um problema verdadeiro, porque ele está colocado em relação a uma única coisa, que tem dois modos (o de ser e o agir) e é um misto de duas tendências que diferem por natureza: a virtual, durante e conceitual; e a atual, realizada em tais ou quais materialidades.

Quando o pesquisador não analisa as duas tendências de uma mesma coisa, mas intenta comparar coisas diferentes, ele chegará a conclusões errôneas, pois não é possível comparar laranjas com melancias, por exemplo. A não ser que laranjas e melancias sejam 
concebidas como duas atualizações da virtualidade fruta, que só existe como conceito (generalidade).

Atual e virtual estão sempre se alternando na intuição que temos da duração. A duração, sob essa perspectiva, seria o fluxo da memória (e das imagens-lembrança) enrolandose ou desenrolando-se em todas as direções possíveis ou, principalmente, imagináveis. Embora o hábito, a necessidade de agir e o pensamento pareçam nos dizer que para ir ao passado precisamos retornar no tempo-espaço histórico desse fluxo, e buscar lá atrás algo que supostamente já foi, para Bergson (2011) trata-se, ao invés, de perscrutar os modos como o passado invade ou assombra o presente, sem anúncio prévio e hora marcada para acontecer ou atualizar-se no presente.

Ou seja, a percepção da matéria de nosso presente está impregnada de lembranças suas, e é a partir dessas que a reconhecemos. 0 re-conhecimento se faz, portanto, desde a memória da coisa, cuja lembrança é, por sua vez, traiçoeira. E não é à toa que Bergson (2011) convoca a noção de déjà-vu em sua obra: de um lado principal e mais genérico para explicar uma das formas de traição da lembrança; e de outro lado - segundo nosso particular interesse de pesquisa -, para ressaltar certos construtos em planos de um filme qualquer na perspectiva de sua potência para evocar lembranças e denunciar (ou problematizar) um suposto déjà-vu.

É assim que, no contexto de seus estudos, principalmente em Matéria e Memória, obra publicada originalmente em 1896, Bergson (2011) rompe com a ideia de que a matéria é que age sobre o espírito, e que é a partir da imagem que se cria o imaginário. ${ }^{4} 0$ que Bergson (2011) propõe, diferentemente, é que a memória é duração e atualiza-se agindo na matéria, e que nela perdura como virtualidade; e que o universo cognoscível é um conjunto de imagens; e é cognoscível a partir do corpo, que também é, nesses termos, imagem: o centro de indeterminação a partir do qual percebemos as demais, e a única imagem que somos capazes de perceber por dentro. Além disso, para Bergson (2011), a memória não está em nós, não nos pertence: nós é que estamos na memória e pertencemos a ela.

A memória pura registra para si todas suas atualizações na matéria e expande-se, incha. Mas, no habituado, nossa percepção não capta, obviamente, todas as imagens do universo, porque são demasiadas: ela seleciona dentre elas apenas as que interessam à nossa ação no presente com vistas à nossa própria e individual sobrevivência. Mas as imagens que

\footnotetext{
4 Essas ideias, criticadas por Bergson (2011), eram defendidas, no início do século XX, por duas correntes filosóficas: o idealismo e o realismo.
} 
não percebemos estão lá na memória pura, e poderão tornar-se úteis à nossa ação em outros presentes e circunstâncias.

São essas imagens "descartadas" as que são acionadas na percepção, já não como memória, mas como imagens-lembrança, aquelas a partir das quais percebemos o presente: é porque há lembrança delas no passado que percebemos as imagens do presente que interessam. As que a cada percepção não são acionadas (porque não estão sendo úteis no momento), permanecem no passado, aguardando a oportunidade de novamente se tornarem úteis no presente.

Podemos subentender, desde tal perspectiva, que há, em um plano qualquer de um filme qualquer, imagens que estão fora do campo de visão, mas que ainda assim pairam no ar e assombram o visível como já visto (lembrança) ou como jamais visto (imaginação). Como "objetos perdidos", tais imagens se movimentam no plano virtual, no enrolar-se e desenrolar-se da memória que dura; e em algum momento do presente, por uma nova necessidade qualquer de agir, logramos alcança-las na lembrança. Bergson (2011, p. 275) ilumina assim nosso entendimento do que está fora do campo visível: “[...] a lembrança é a representação de um objeto ausente.".

É neste contexto que Bergson (2011) afirma que, se a percepção é nossa, o percepto, no entanto, está nas coisas e não em nós. No plano virtual, todas as coisas estão sempre presentes, passíveis de serem vistas, agidas e representadas. Enquanto o corpo age sobre apenas uma imagem, existe uma multiplicidade de outras imagens ao seu redor das quais, ainda que não as percebamos, sentimos a presença, a assombração. Também não é o sujeito que possui as imagens, mas o contrário: as imagens é que possuem o sujeito. Como na visão aurática em Benjamin, em que a imagem, estando perto ou longe, se apodera de nós.

Para Bergson (2011) agimos, conscientemente, no espaço, em função das necessidades do presente e pensando no futuro. Tais ações são demandadas pelo "hábito" e pela "utilidade". O mais interessante, porém, é que isso vale para todos os corpos, para todas as coisas, que têm, todas - repetimos -, dois modos: o de ser e o de agir. Todas as coisas são corpos dotados de memória, e todas as coisas duram como virtualidade (no tempo) e se atualizam na matéria (no espaço).

Então, desde tal perspectiva, a imagem enquadrada em um filme é uma das formas de agir da imagem fílmica (ou mesmo da cinematográfica, ou mesmo de uma imagem qualquer, dependendo de como construímos nosso objeto de pesquisa como um misto de duas tendências: uma, virtual, e a outra, a de sua realização na matéria ou espaço visível que 
compõe o corpus de nossa pesquisa). Já quanto ao seu modo de ser, há que se considerarem também os devires não enquadrados - nesse filme, ou nesse plano -, porquanto eles relacionam-se à potência dessa imagem.

O visível e o invisível alternam-se e diferenciam-se, assim, no plano, mais em termos de tempo do que de espaço, porquanto um é a tendência virtual do outro. Quando a câmera movimenta-se, algo muda substancialmente: não se trata apenas do espaço percorrido pela câmera, que vai assim dando a ver coisas diferentes presentes no cenário. Na mudança de planos, o invisível já foi ou ainda poderá ser visto, por exemplo, porque ele é parte da memória pura do filme, imagem-lembrança de algum momento desse filme. Nesse caso, o invisível está disponível para realizar-se visivelmente, a qualquer momento.

Ou seja, a imagem invisível sempre está no quadro, como virtualidade; quando se torna visível, é porque ela passou a ser ou voltou a ser útil à narrativa. Assim, a imagem invisível em um quadro qualquer sobeja e aspira tornar-se visível, no mesmo plano ou em outro plano: ela é a potência do visível (gravado) no filme (editado) ao qual o espectador assistirá.

Há que se considerar ainda que todas as imagens de um filme realizem-se em última instância ao serem exibidas. 0 corpo do espectador não é o corpo do filme, nem o de seu realizador, nem o corpo do cinema, e nem sequer o corpo da imagem, visível ou invisível. Dentre esses corpos, o do espectador é o centro de indeterminação a partir do qual todas as demais imagens são percebidas, sendo que participam de sua percepção (no momento da exibição) as imagens-lembrança que ele tem de quadros e planos do filme, de outros quadros e planos de outros filmes: os perceptos do objeto. Essas são as que, quando invisíveis no quadro, deixam rastros no visível de um plano ou conjunto de planos. Ou seja, essas são relativas ao espaço ou à espacialização da duração do plano cinematográfico.

Entretanto, há que se considerar também que durante a exibição (e às vezes apenas após) outras imagens-lembrança (de outros quadros e planos, que transcendem os quadros e planos do filme e do cinema) são acionadas pelo espectador: os afectos do sujeito. Essas são as que não deixam rastros visíveis em nenhum quadro ou plano de um filme qualquer, mas que, apesar disso, podem ser intuídas, porquanto agem decisivamente sobre a percepção, e acabam sendo autenticadas pelo espectador-pesquisador como imagens "vistas". Ainda que estejam materialmente ausentes de qualquer quadro do filme, tais imagenslembrança o atravessam. E preenchem lacunas imagéticas que são inevitáveis sob a técnica de fragmentação e montagem - essenciais à narração no cinema - com presumidos (lembrados ou imaginados) do espectador. 


\section{Rastros do invisível em $O$ Eclipse}

Os enquadramentos e a montagem dos planos do filme $O$ Eclipse muitas vezes apontam para o que está em outro lugar ou tempo da narrativa: personagens, cenários, objetos e diálogos desaparecem da cena e se deslocam para um plano não visto. Isto faz com que as imagens de Antonioni não sigam a centralidade e objetividade do olhar clássico, porque existe uma abertura da dimensão do quadro em que, nem sempre, o que está enquadrado é o que mais interessa.

É assim que, no plano do diretor - especialmente, na sequência final, já mencionada aqui, o ponto de vista da câmera abandona os personagens e os seus dramas e se volta para espaços "vazios" de personagens e de objetos que tenham sido vistos durante o desenrolar da trama, sugerindo haver outras narrativas quaisquer de dramas quaisquer de personagens quaisquer, os quais estiveram sempre, no entanto, subsumidos ou adjacentes aos quadros e aos planos vistos. 0 visível nesses "vazios" é como a imagem de uma reserva da potência (eclipsada), a qual, agora, age sobre o filme percebido, demandando do espectador uma ação que é de ordem memorial, de um lado, e de ordem imaginativa de outro lado.

Mas mesmo em outras sequências, anteriores, há imagens eclipsadas, como, por exemplo, nas evitadas e fugidias trocas de olhares entre os personagens, ressaltando a incomunicabilidade entre eles; ${ }^{5}$ bem como nas vistas do plano e do quadro oferecidas ao espectador e aos personagens: enquanto o espectador vê coisas que os personagens não vêem, os personagens vêem coisas que estão fora de quadro, e que o espectador apenas pode depreender, sendo que isso demanda do espectador perscrutar o olhar do personagem em busca de uma presença que está de fato ausente do quadro ou plano.

Assim, temos que a recorrente mise-en-scène da personagem principal, Vittoria, muitas vezes de costas para a câmera, demonstra que ela sempre esconde algo, tanto dos outros personagens quanto do espectador, ainda que o seu olhar às vezes descubra coisas que não estão ao alcance dos demais. 0 olhar do cineasta, rastreado pelo enquadramento da câmera (e pela edição, ao final), é o que intenta montar as vistas presentes e ausentes como se houvesse conexão entre elas. 0 cineasta, nesse caso, tende a abrir o quadro e a alternar o visível e o invisível, e a jogar com os olhares implicados na significação da narrativa. Em $O$ Eclipse, a imagem invisível não deixa de existir e agir porque o espectador não a vê; perder de vista

\footnotetext{
5 O filme $O$ eclipse faz parte da chamada "Trilogia da Incomunicabilidade" realizada por Antonioni. A aventura (1960) e $A$ noite (1961) completam a trilogia.
} 
certos corpos-imagens não significa "perder a vista", deixar de perceber o mundo, cegar-se. Talvez, ao contrário, perder de vista implique ou demande do espectador ampliar sua visão, intuir e incluir no regime de visibilidade aquelas imagens mais distantes no tempo, que retornam no presente, de outra forma, acionadas por imagens da memória.

Ou seja, o invisível no plano cinematográfico se realiza (e pode ser percebido, portanto, enquanto tal) porque existe uma memória do visível. Toda a questão remete, então, à ação da memória, que é convocada, em última instância, pelo espectador: é ele que supre com suas próprias lembranças as lacunas imagéticas do enquadramento, mesmo quando não há, nele, rastros visíveis do invisível, e mesmo quando não se trata da produção de presença do ausente.

\section{Considerações finais}

Nos termos que estamos propondo nesse artigo, a imagem espacializada (visível em uma materialidade qualquer) carrega consigo, imbricada nela, incrustada nela, imagens invisíveis de sua duração.

Isso diz respeito a qualquer forma de enquadramento do visível com vistas à percepção: sempre recortamos da coisa apenas o que dela nos interessa para agir no presente. Para a percepção de qualquer coisa são convocadas da memória apenas aquelas imagenslembrança (as que "já foram vistas" anteriormente) que são úteis ao "reconhecimento" do que precisamos para uma ação qualquer.

Se o mecanismo da percepção não foi inventado pelo cinema, foi ele, no entanto que o praticou e o deu a ver sobremaneira. Expressões como "enquadramento", "corte" e "montagem" surgiram da análise da técnica significante na realização e espectação de filmes; mas, de fato, tais procedimentos já existiam antes e transcendem de longe a técnica do cinema.

Tanto Benjamin (2012) quanto Bergson $(2011)^{6}$ deram-se de conta de que os modos do cinema tensionavam as então clássicas teorias da arte, que também versavam sobre a produção de sentido na relação entre obra e espectador, e sugeriram alternativas ao entendimento do que possa ser ver ou perceber "algo" em uma imagem. Ambos, cada um a seu modo, aludiram à presença de uma ausência que age na percepção, tida por eles como inexorável e decisiva ao entendimento.

\footnotetext{
6 E é impossível não lembrar aqui as teorizações, afins, de Eisenstein, especificamente sobre o cinema.
} 
Em Benjamin (2006), tratava-se da aura de uma obra, ou o vestígio do passado na imagem do presente, que, por mais perto que se esteja da obra, nunca é alcançado objetivamente, porque é da ordem da experiência, única, de cada espectador. Na relação do espectador com a obra haveria sempre uma dupla distância que se teria que considerar na análise da obra: a de sua materialidade (visível, na forma impotente realizada no presente) e a de sua imaterialidade (invisível, na forma potente de um passado não realizado).

Em Bergson (2011), tratava-se da duração, da qual, em cada obra, apenas se percebe, habitualmente, uma de suas duas tendências: a de sua atualidade, visível objetivamente na forma realizada no espaço ou na matéria. Sua outra tendência, a de sua virtualidade, é invisível, mas pode ser subjetivamente intuída e produzir um efeito de presença. Transcendendo o hábito, pela observação atenta e desinteressada (no presente), alcançaríamos outras imagens-lembranças do cone da memória - através da afecção, e não da percepção.

\section{Referências}

AGAMBEN, Giorgio. 0 que é o contemporâneo? E outros ensaios. Chapecó: Argos, 2009.

BALAZ, Bela. A face das coisas. In: XAVIER, Ismail (Org.). A experiência do cinema. 4. ed. Rio de Janeiro: Graal, 2008, p. 77 a 83.

BAZIN, André. 0 cinema: ensaios. São Paulo: Brasiliense, 1991.

BELLOUR, Raymond. Entre-imagens, foto, cine e vídeo. Campinas, SP: Papirus, 1990.

BENJAMIN, Walter. Passagens. Belo Horizonte: UFMG, 2006.

BENJAMIN, Walter. A obra de arte na época de sua reprodutividade técnica. Porto Alegre: Zouk, 2012.

BENJAMIN, Walter. Magia e técnica, arte e política. São Paulo: Brasiliense, 1989.

BERGSON, Henri. Matéria e memória. São Paulo: Martins Fontes, 2011.

BONITZER, Pascal. El Campo ciego: ensayos sobre el realismo en el cine. Buenos Aires: Acos, 2007.

CLARY, Jonathan. A visão que se desprende: Manet e o observador atento no final do século XIX. IN: CHARNEY, Leo; SCHWARTZ, Vanessa (Org.) 0 cinema e a invenção da vida moderna. São Paulo: Cosac Naify, 2004.

DELEUZE, Gilles. A Imagem-Movimento São Paulo: Ed. Brasiliense, 1985.

DIDI-HUBERMAN, Georges. 0 que vemos, o que nos olha. São Paulo: 34, 2010. 
EISENSTEIN, Sergei. A forma do filme. Rio de Janeiro: Zahar, 2002.

GAGNEBIN, Jeanne Marie. Apagar os rastros, recolher os restos. In: SEDLMAYER, Sabrina; GINZBURG, Jaime (Org.). Walter Benjamin: rastro, aura e história. Belo Horizote: UFMG, 2012, p. 27 a 38.

GRÜNEWALD, José Lino. (trad. e org.). A Ideia do Cinema: Ensaios de Walter Benjamin, Eisenstein, Godard, Merleau-Ponty. Rio de Janeiro: Civilização Brasileira, 1969.

GUMBRECHT, Hans Ulrich. Produção de presença: o que o sentido não consegue transmtir. Rio de Janeiro: Contraponto, 2010.

MÜNSTERBERG, Hugo. A atenção; a memória e a imaginação e as emoções. In: XAVIER, Ismail (org.) A experiência do Cinema. Rio de Janeiro, Edições Graal: Embrafilme, 2008.

VERTOV, Dziga. Resolução do conselho dos três. In: XAVIER, Ismail (org.) A experiência do Cinema. Rio de Janeiro, Edições Graal: Embrafilme, 2008.

\title{
The Invisible in the Cinematographic Plane:
}

\section{Traces of Benjamin and Bergson}

\begin{abstract}
In this article we explore forms of presence and absence in the framings and perception of the spectator based on scenes and frames from the film The Eclipse (1962) by Michelangelo Antonioni. We find in the director's intention in realizing this film what we call the "eclipse of visuality," that is, traces between the visible and the invisible in the montage of the cinematographic planes. The intrinsic time of the montage causes the frames to return in another manner, relate to other frames and above all, to leave traces in the landscape of images and sounds in movement. In this discussion about traces of the invisible and the memory of the visible, we deepen the specular concepts of traces and aura in Benjamin and contrast them with the concepts of time and memory in Bergson.
\end{abstract}

\section{Keywords}

Cinema. Film plane. Eclipse of Visuality. Traces. Memory. 